\title{
Study of harmonic propagation in transmission networks with high penetration of power electronics devices
}

DOI:

10.1109/PTC.2017.7980848

\section{Document Version}

Accepted author manuscript

Link to publication record in Manchester Research Explorer

\section{Citation for published version (APA):}

Abdelrahman, S., Wang, M., Milanovic, J. V., \& Becirovic, E. (2017). Study of harmonic propagation in transmission networks with high penetration of power electronics devices. In Study of harmonic propagation in transmission networks with high penetration of power electronics devices https://doi.org/10.1109/PTC.2017.7980848

Published in:

Study of harmonic propagation in transmission networks with high penetration of power electronics devices

\section{Citing this paper}

Please note that where the full-text provided on Manchester Research Explorer is the Author Accepted Manuscript or Proof version this may differ from the final Published version. If citing, it is advised that you check and use the publisher's definitive version.

\section{General rights}

Copyright and moral rights for the publications made accessible in the Research Explorer are retained by the authors and/or other copyright owners and it is a condition of accessing publications that users recognise and abide by the legal requirements associated with these rights.

\section{Takedown policy}

If you believe that this document breaches copyright please refer to the University of Manchester's Takedown Procedures [http://man.ac.uk/04Y6Bo] or contact uml.scholarlycommunications@manchester.ac.uk providing relevant details, so we can investigate your claim.

\section{OPEN ACCESS}




\title{
Study of Harmonic Propagation in Transmission Networks with High Penetration of Power Electronics Devices
}

\author{
Sami Abdelrahman, Graduate Student Member, IEEE, Mengxuan Wang, Jovica V. Milanović, Fellow, IEEE and \\ Elvisa Bećirović, Member, IEEE \\ School of Electrical and Electronic Engineering \\ The University of Manchester \\ Manchester, UK \\ milanovic@manchester.ac.uk
}

\begin{abstract}
Power Quality (PQ) disturbances result in significant financial losses to both network operators and end users. With the increasing regulatory requirement to monitor and improve $P Q$, the mitigation of $P Q$ disturbances becomes even more important. This paper focuses on assessment of the harmonic performance at transmission network level considering increasing presence of stochastic and intermittent power electronics (PE) interfaced distributed generation (DG) in the network. A number of case studies considering different levels of penetration and types of DG are performed attempting to correlate the level of DG penetration with the harmonic performance. The propagation studies are performed using probabilistic harmonic load flow. The network model adopted for the studies is 68-bus of the New England Test System and the New York Power System.
\end{abstract}

Index Terms - benchmarking, distributed generation, harmonics modelling, probabilistic analysis

\section{INTRODUCTION}

Harmonics are sinusoidal voltages or currents with frequencies which are integer multiples of the fundamental frequency in the network [1]. The main causes of harmonics are (i) saturable devices due to the physical characteristics of the iron core (e.g. transformers and rotating machines), (ii) arcing devices due to the physical characteristics of the electric arc (e.g. furnaces and fluorescent lighting) and (iii) power electronics due to semiconductor device switching (e.g. variable speed drives (VSD) interfaced motors and converter interfaced generators). The third category can be considered the main reason for renewed interest in the harmonic phenomenon, especially in the transmission levels, and the need for new models and mitigation techniques. The power electronic interfaced loads and generators involve high level of uncertainties in both general performance and harmonic emission. Output level, location (e.g. Electric Vehicles and intermittent DG) and switching frequency are examples of variable factors that might affect the harmonic performance of networks and the selection of mitigation techniques.

This work was supported by MIGRATE project under Grant No 691800
The general methodology for simulating the system harmonics performance can be divided into three steps: injecting different level of harmonic currents of the considered frequencies at certain locations in the network, calculating the different spectra of the voltage and currents over a window of time at all network components, and then calculating the required indices from the spectra recorded at the different locations in the network. Several indices are developed to describe the harmonics phenomenon; the most common indices are the Total Harmonic Distortion (THD) for the voltages and currents and can be calculated by (1) for the voltage distortion,

$$
T H D=\sqrt{\sum_{h=2}^{\infty} V_{h}^{2}} / V_{1}
$$

where $V_{h}$ is the voltage at the harmonic frequency $h$ and $V_{l}$ is the voltage at the fundamental frequency. The calculated indices are described statistically; i.e., the $95 \%$ or $99 \%$ of the sample or the maximum value can be used to describe the performance with comparison to standards $[2,3]$.

The effects of the DG penetration on the PQ performance have been studied in a number of publications. The DG penetration level effects, on the voltage sags only, were studied in [4]. The DG penetration level impact on the harmonic performance is studied in [5]. The authors introduced the concept of hosting capacity based on PQ performance. The impact of the DG on the harmonic performance was also studied in [6] focusing on the interactions between DG invertor emissions and the grid background harmonic pollutions. Similarly, [7] investigated the impact of wind turbines on the harmonic performance. The impact of the PV and storages connections on a distribution feeder was studied in [8]. The phenomena of voltage regulation, unbalance and harmonics were analysed under different levels of DG penetration.

This paper discusses a simulation framework for studying harmonic propagation in PE rich transmission networks. A number of case studies and future scenarios are adopted to 
evaluate the harmonic performance of transmission network with high penetration of PE interfaced DG. Different assumptions in the models are discussed and evaluated, for example considering injections of high frequency harmonics (> $2 \mathrm{kHz}$ ) and the justification or not for modelling of the resistance frequency dependency of transmission lines. The paper adopts probabilistic harmonic load flow for the evaluations of harmonic performance over weeklong performance studies. The model adopted for the studies is the 68-bus NETS-NYPS network.

\section{TEST SYSTEM}

\section{A. The network models}

The simulation test system adopted is the NETS-NYPS network with 20 buses with DG connections added to the original system. It is a $230 \mathrm{kV}$ transmission system which consists of 68 buses, 16 synchronous generators, and 35 loads with different ratio of nonlinearity considered for different loads. The nonlinear portions of the loads are modelled based on their Norton equivalent (i.e. independent harmonic current source in parallel with an admittance matrix) as shown in Fig. 1 , and the linear loads based on their equivalent impedance model.

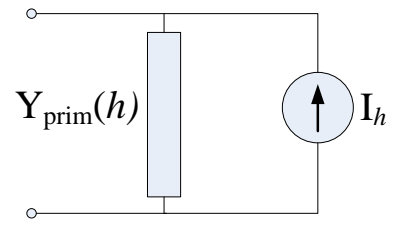

Figure 1. Norton equivalent modelling of harmonic sources

The transmission lines are modelled based on the distributed parameters of the lines. The frequency dependency of the lines resistance was considered in some of the case studies, as discussed in the next section. The $\mathrm{R}(f)$ modelling was based on equation (2) [1], while the inductance $\mathrm{L}$ and capacitance $\mathrm{C}$ of the network components are assumed independent of the frequency, so the line impedance is given by (3)

$$
\begin{aligned}
& R_{h}=R_{1} \times \sqrt{h} \\
& Z_{h}=R_{1} \times \sqrt{h}+j h_{\omega_{0}} L
\end{aligned}
$$

An hourly operation for one week was adopted for the studies. The load demand curve is based on an hourly demand for a week period extracted from the UK demand curve [9]. The DG units were assumed uncurtailable and the disconnection of the conventional generation was calculated from the optimal power flow (OPF) results. The system was modelled in DIgSILENT PowerFactory environment, with the synchronous generators outputs determined based on OPF results at each hour performed in MATPOWER. Further details about the model can be found in [10].

\section{B. Integration of $D G$}

Twenty buses from the network are selected for the DG connection. 10 PV units with 6-pulse invertor interfaces and 10 wind turbines units modelled as double fed induction machines (DFIG) are connected. The single PV unit is a 2 MW and 0 MVAr rated output, with the total output of a plant varies based on the number of parallel units connected (the smallest plant is with 35 units connected, i.e. $70 \mathrm{MW}$ maximum output). Similarly for the wind plants, the single wind turbine unit is a $2 \mathrm{MW}$ and $0.25 \mathrm{MVAr}$ rated output, with the smallest wind plant having 67 wind turbine units connected.

The wind and photovoltaic generators have an annual hourly output curves, extracted from realistic outputs data based on the UK weather [11, 12]. Two different output curves are adopted for the PV units and two curves for the wind plants, as shown in Fig. 2. This is to account for the variability in DG outputs based on the connection location.

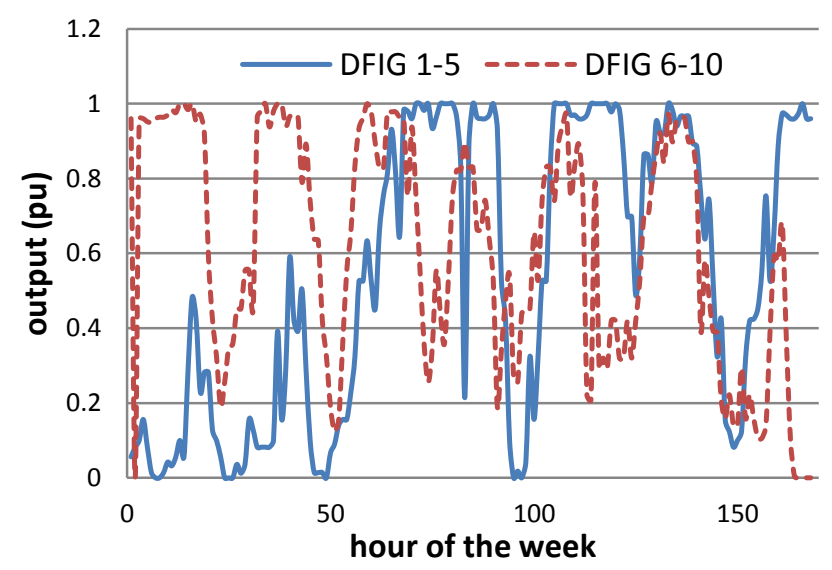

(a) Wind profile

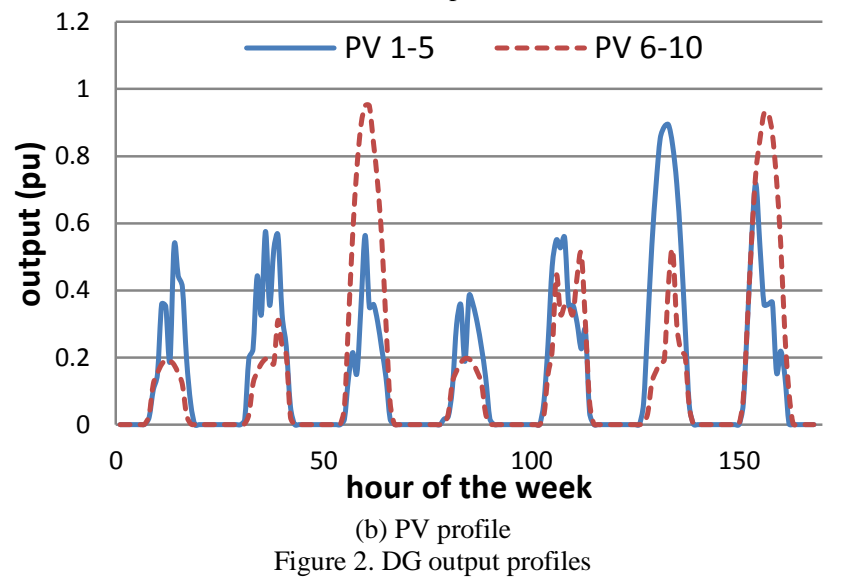

III. METHEDOLOGY

\section{A. Case studies and scenarios}

A number of case studies were adopted to analyze and evaluate the harmonic propagation in transmission networks. The basic case study with renewables connected is based on the penetration level of the 20 added DG units which considering their full rating accounts for $30 \%$ of the network generation. The penetration level is calculated as the ratio between the total DG connected output at a certain hour and the total demand at that hour. Hence, the penetration level varies during the study period (one week). As mentioned, the disconnection of the conventional generation is determined based on the OPF studies to ensure that no network operational limit violations occur. The ratings of all DG units 
were then increased gradually and uniformly, and OPF results for each hour of the study week were checked and benchmarked against network operational limits. The maximum DG penetration recorded was $70 \%$, recorded during the morning hours where a high wind and a relatively high PV outputs coincided with low load level. Fig. 3 shows one day generation type mix in which the maximum DG penetration occurred.

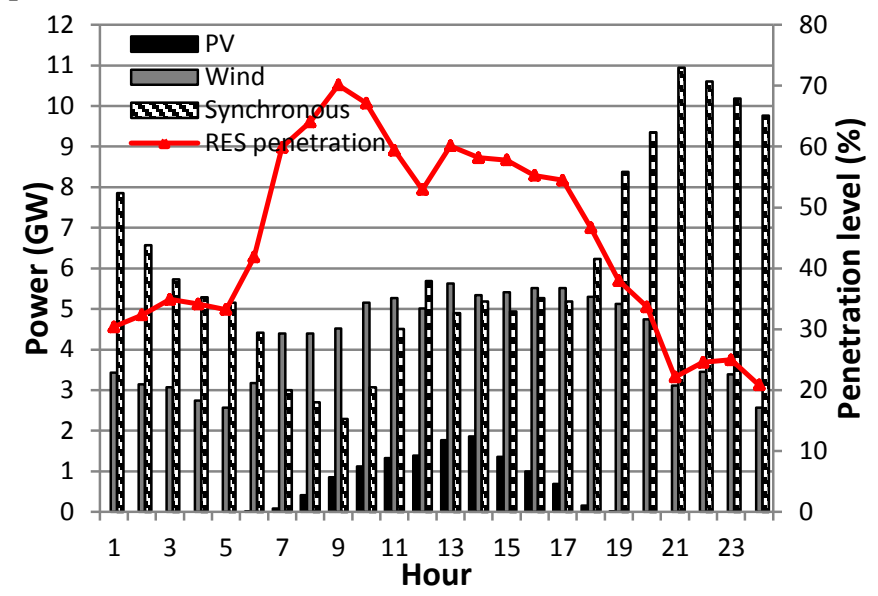

Figure 3. One day generation mix and RES penetration level

The harmonic performances of the following four case studies are analysed and compared:

- Case 1: Loads are nonlinear - no DG connected

- Case 2: Loads are linear with 30\% DG penetration

- Case 3: Loads are nonlinear with 30\% DG penetration

- Case 4: Maximum possible DG penetration based on OPF convergence.

In the above cases, the harmonic frequencies considered are the first four characteristic frequencies of the six pulse converters $\left(5^{\text {th }}, 7^{\text {th }}, 11^{\text {th }}\right.$ and $\left.13^{\text {th }}\right)$. However, in future transmission networks with the increased penetration of high frequency switching multi-level converters, high frequency harmonics cannot be neglected in the evaluation. For the basic case study (Case 1), further analysis is performed considering harmonics in the range $2 \mathrm{kHz}-10 \mathrm{kHz}$ [13]. Two more case studies are adopted to evaluate the high frequency harmonics presence:

- Case 5: Adding $49^{\text {th }}$ and $199^{\text {th }}$ harmonic injections (to mimic harmonic injections by converters of switching frequencies in the range between $2 \mathrm{kHz}$ and $10 \mathrm{kHz}$ ) to the basic case studies without modelling resistance frequency dependency.

- Case 6: Adding 49 $9^{\text {th }}$ and $199^{\text {th }}$ harmonic injections to the basic case studies with basic modelling of resistance dependence on frequency.

\section{B. Probabilistic harmonic load flow}

The time-series harmonic probabilistic simulation is performed using DIgSILENT PowerFactory. In the network, the locations of the harmonic sources are at the buses with predefined nonlinear loads and DG connected. In the simulations all the sources are modelled as the Norton equivalent of the source (see Fig. 1).
In the case studies where the nonlinearity of the loads is considered, the nonlinear ratio of the loads was randomly selected between $20-40 \%$ of the load size. Each harmonic current injection (magnitude and angle), for each phase, are varied randomly by sampling uniform distributions within given ranges using Monte Carlo (MC) simulations technique. The ranges are determined based on standards and documented harmonic performance of selected power electronics devices (PE interfaced DG and loads). The low frequency harmonics were up to $1 \sim 1.5 \%$ based on recorded measurement at distribution networks [14], the $49^{\text {th }}$ harmonic was modelled with a maximum of $0.15 \%$ which is the IEEE standard limit of the allowed injections of large loads $(25 \leq$ $\mathrm{I}_{\mathrm{sc}} / \mathrm{I}_{\mathrm{L}}<50$ ) connected at voltages $>161 \mathrm{kV}$ [3], and the injections at the $199^{\text {th }}$ harmonic are up to $0.8 \%$ of fundamental current based on the results shown in [15] for the superharmonic range of injections of a multi-level converter. The angles range is (0-180) degrees for all harmonic sources. For example, for a 100 A fundamental current load, if the sampled ratio of nonlinearity was $25 \%$, and the sampled $5^{\text {th }}$ harmonic injection was $1 \%$, that will yield a $5^{\text {th }}$ harmonic current injected at the connection bus of a value of $100 \times 0.25 \times 0.01=$ $0.25 \mathrm{~A}$. Thus at a certain operating point, a single harmonic simulation is performed by injecting random values, from the predefined ranges, of harmonic currents from fixed locations in the network and then a harmonic load flow is run. A high number of harmonic simulations is performed to reach constant average THD values at certain validating buses. The next operating point is then considered (new generation/load level, new topology, switching status of capacitors, etc.) and the same harmonic simulation procedure is followed, Fig. 4 shows the flowchart of the algorithm.

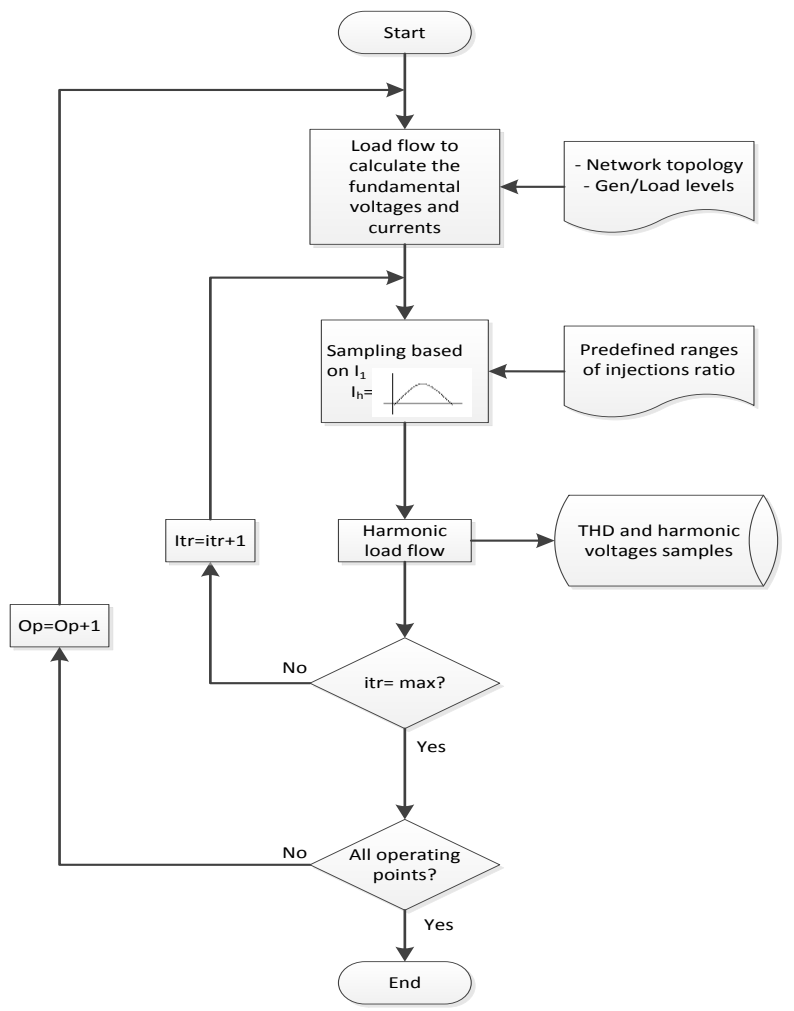

Figure 4. Probabilistic harmonic load flow algorithm 


\section{RESULTS AND ANALYSIS}

The results of the harmonic performance evaluation are based on the week $95^{\text {th }}$ percentiles values of THD, taking the worst phase THD as the bus measure. A comparison was performed between the cases to identify the worst performing buses based on the sources of harmonics (i.e. loads or DG).

Case 3 results can be useful in quantifying the THD increase (and sometimes decrease) due to the addition of the DG harmonics to the original case (Case 1). Table I shows the worst performing buses in terms of THD in the cases 1 to 4 . As it can be seen in the table, buses 48, 47 and 27 are among the worst in all the cases, showing that some areas of the network are more prone to harmonic distortion regardless of the location of injections. This could be due to the frequency impedance characteristics of the buses in these areas. Moreover, by comparing THD values of cases 3 and 4, Bus 40 showed the maximum increase ratio in THD, around $15.5 \%$. Having in mind that the penetration level was increased by more than the double between the two cases, these results showed that the harmonic performance may not be directly proportional to the DG penetration level.

TABLE I: The Worst PeRforming Buses IN The CASES 1-4

\begin{tabular}{|c|c|c|c|c|c|c|c|}
\hline \multicolumn{2}{|c|}{ Case 1 } & \multicolumn{2}{c|}{ Case 2 } & \multicolumn{2}{c|}{ Case 3 } & \multicolumn{2}{c|}{ Case 4 } \\
\hline Bus & $\begin{array}{c}\text { THD } \\
(\%)\end{array}$ & Bus & $\begin{array}{c}\text { THD } \\
(\%)\end{array}$ & Bus & $\begin{array}{c}\text { THD } \\
(\%)\end{array}$ & Bus & $\begin{array}{c}\text { THD } \\
(\%)\end{array}$ \\
\hline B 48 & 3.84 & B 48 & 1.49 & B 48 & 4.94 & B 48 & 5.21 \\
\hline B 40 & 3.56 & B 47 & 1.44 & B 40 & 4.51 & B 40 & 5.21 \\
\hline B 47 & 3.42 & B 27 & 1.38 & B 47 & 4.39 & B 47 & 5.06 \\
\hline B 27 & 2.67 & B 64 & 1.34 & B 27 & 3.34 & B 46 & 3.71 \\
\hline B 26 & 2.66 & B 66 & 1.33 & B 26 & 3.32 & B 27 & 3.65 \\
\hline
\end{tabular}

When considering the high frequency harmonics in the evaluation, new buses appeared in the worst performing group of buses. This is mainly due to high frequency resonance excited at or near those buses. Table II, shows the ranks of the worst performing buses in Case 5 and Case 6. As shown in the table, buses 64 and 17 are the worst performing in cases 5 and 6 respectively. The damping effect of modelling $\mathrm{R}(f)$ can be noticed in the lower values of the THD in Case 6 (the worst bus recording $3.59 \%$ ).

TABLE II: The Worst Performing Buses IN The CASEs 5 ANd 6

\begin{tabular}{|c|c|c|c|}
\hline \multicolumn{2}{|c|}{ Case 5 } & \multicolumn{2}{c|}{ Case 6 } \\
\hline Bus & THD (\%) & Bus & THD (\%) \\
\hline B 64 & 5.39 & B 17 & 3.59 \\
\hline B 48 & 4.80 & B 48 & 3.15 \\
\hline B 17 & 4.77 & B 64 & 3.04 \\
\hline B 40 & 4.44 & B 47 & 2.95 \\
\hline B 47 & 4.30 & B 40 & 2.87 \\
\hline
\end{tabular}

Fig. 5 shows a comparison between the results of Case1, Case 5 and Case 6 showing the $95^{\text {th }}$ percentiles of the THD of the worst phase for all the buses that appeared among the worst buses in any of these case studies. It can be clearly seen that the addition of the high frequency harmonics increases the THD at almost all buses, if the $\mathrm{R}(f)$ modelling is neglected, i.e. Case 5. Buses 26 and 27 showed negligible difference in THD between the cases as shown in the figure.

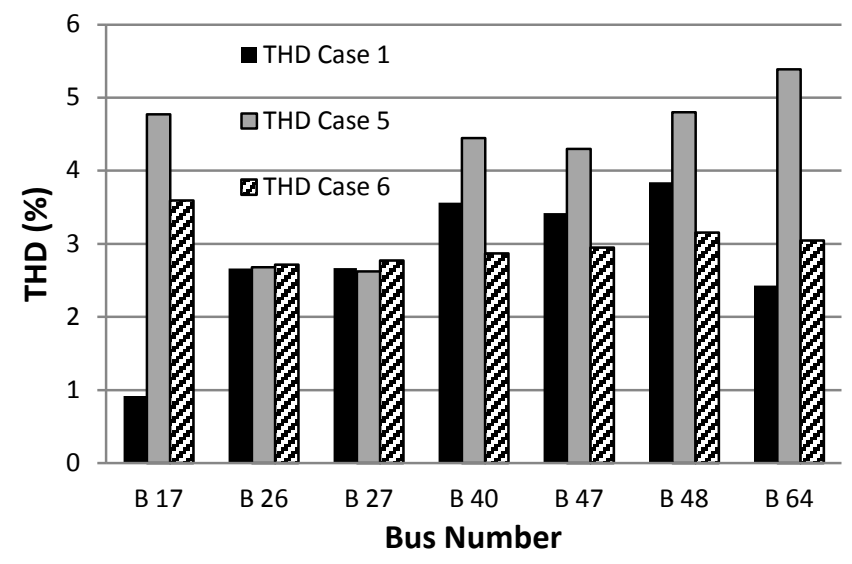

Figure 5. Comparisons between Case 1, Case 5 and Case 6 results

For Case 5 and Case 6, the individual harmonic voltages were recorded for the worst performing buses. Table III (a) and (b) show the $95^{\text {th }}$ percentiles of the $13^{\text {th }}, 49^{\text {th }}$ and $199^{\text {th }}$ harmonic voltages for the both cases. It can be clearly seen in the tables that buses 64 and 17 are the worst performing in cases 5 and 6 respectively, due to their poor performance with the added high frequency harmonics. This indicates resonance problem at these buses at or near these frequencies.

TABLE III: Harmonic Voltages of The Worst Performing Buses

(a) Case 5

\begin{tabular}{|c|c|c|c|c|}
\hline Bus & THD $(\%)$ & V13 $(\%)$ & V49 $(\%)$ & V199 $(\%)$ \\
\hline B 64 & 5.39 & 1.33 & 5.29 & 0.08 \\
\hline B 48 & 4.80 & 4.11 & 0.43 & 0.03 \\
\hline B 17 & 4.77 & 0.79 & 0.49 & 4.66 \\
\hline B 40 & 4.45 & 3.86 & 0.31 & 0.01 \\
\hline B 47 & 4.30 & 3.61 & 0.10 & 0.02 \\
\hline
\end{tabular}

(b) Case 6

\begin{tabular}{|c|c|c|c|c|}
\hline Bus & THD (\%) & V13 (\%) & V49 $(\%)$ & V199 (\%) \\
\hline B 17 & 3.59 & 0.71 & 0.43 & 3.52 \\
\hline B 48 & 3.15 & 1.90 & 0.27 & 0.04 \\
\hline B 64 & 3.04 & 1.04 & 2.27 & 0.07 \\
\hline B 47 & 2.95 & 1.73 & 0.05 & 0.03 \\
\hline B 40 & 2.87 & 1.80 & 0.19 & 0.01 \\
\hline
\end{tabular}

To further investigate the resonance problem, frequency scans were performed at Bus 64 for both Case 5 and Case 6 , as shown in Fig 6 (a) and (b). It is important to note that modelling the increase in resistance of the network with the increase in harmonic frequency does not always mean an increase in the network impedance $\mathrm{Z}(f)$. Quite the contrary, modelling $\mathrm{R}(f)$ damp the impedance frequency scans peak, as shown in the figure, and subsequently the amplification of the harmonic voltages at the resonance frequencies. Equation 4 [1] shows that the amplification factor $A_{f}$ of harmonic voltages at resonance frequency $h_{r}$ is inversely proportional to the supply resistance,

$$
A_{f}=\frac{X_{s}}{R_{s}} \cdot h_{r}
$$




\section{ACCEPTED VERSION OF THE PAPER}

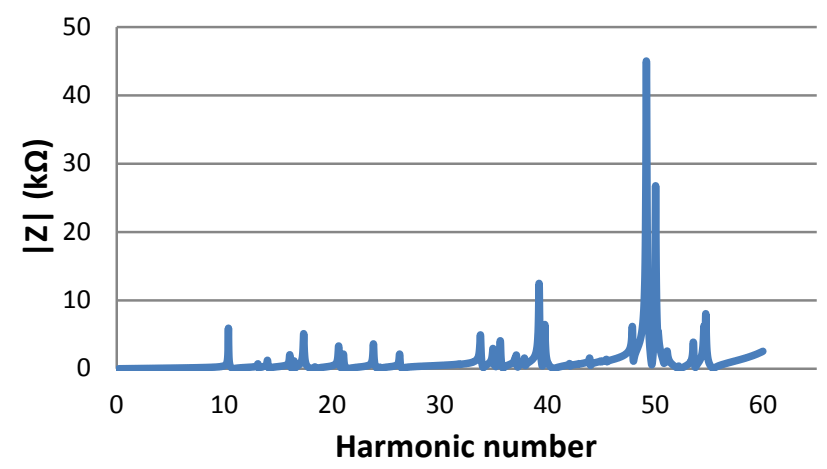

(a) Case 5

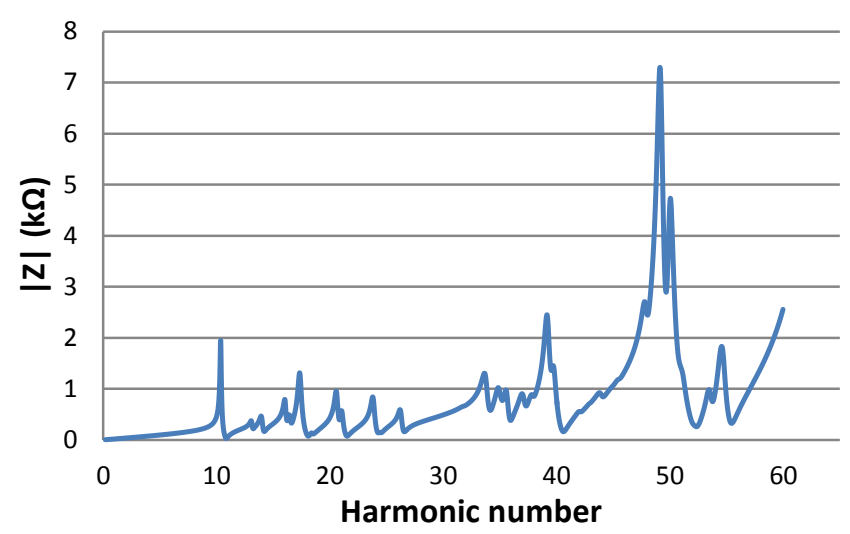

(b) Case 6

Figure 6. Network frequency scan at Bus 64

From the figure, it can be clearly seen that there was resonance problem at Bus 64 around the 49th harmonic. By comparing the frequency scans in Fig 6 (a) and (b), the difference in the damping due to modelling the resistancefrequency dependency can be clearly seen.
To analyse the overall change in network harmonic performance due to resistance modelling, Fig. 7 shows the $95^{\text {th }}$ percentiles values of THD at all network buses. The average overall decrease in the harmonic performance as a result of the resistance modelling can be considered insignificant, around $0.16 \%$, however the performance change is not uniform between all buses. Some buses, like bus 64 , showed more than $40 \%$ decrease in the THD values. On the other hand some other buses, like buses 57-60 showed slight THD increase between cases 5 and 6, i.e., showed worse performance even when considering the resistance dependency.

\section{CONCLUSION}

The increase of the PE interfaced generation is expected to increase the harmonic distortion in the network. This increase is not expected to be linear, as many factors affect the propagation of harmonics through the network. One clear observation from the results is that the worst performing area does not change significantly with the penetration level, although the temporal and spatial variations are considered in the probabilistic evaluation by having different output profiles of the DG units connected at different buses.

Modelling resistance dependency can be omitted when studying low frequency harmonics only. However, when studying propagation of higher order harmonics modelling of resistance dependence on frequency is critical, especially if resonances are expected to be excited by harmonic injections. Neglecting resistance dependence on frequency while evaluating the propagation of high frequency harmonics will lead to overestimation of harmonic values at network buses.

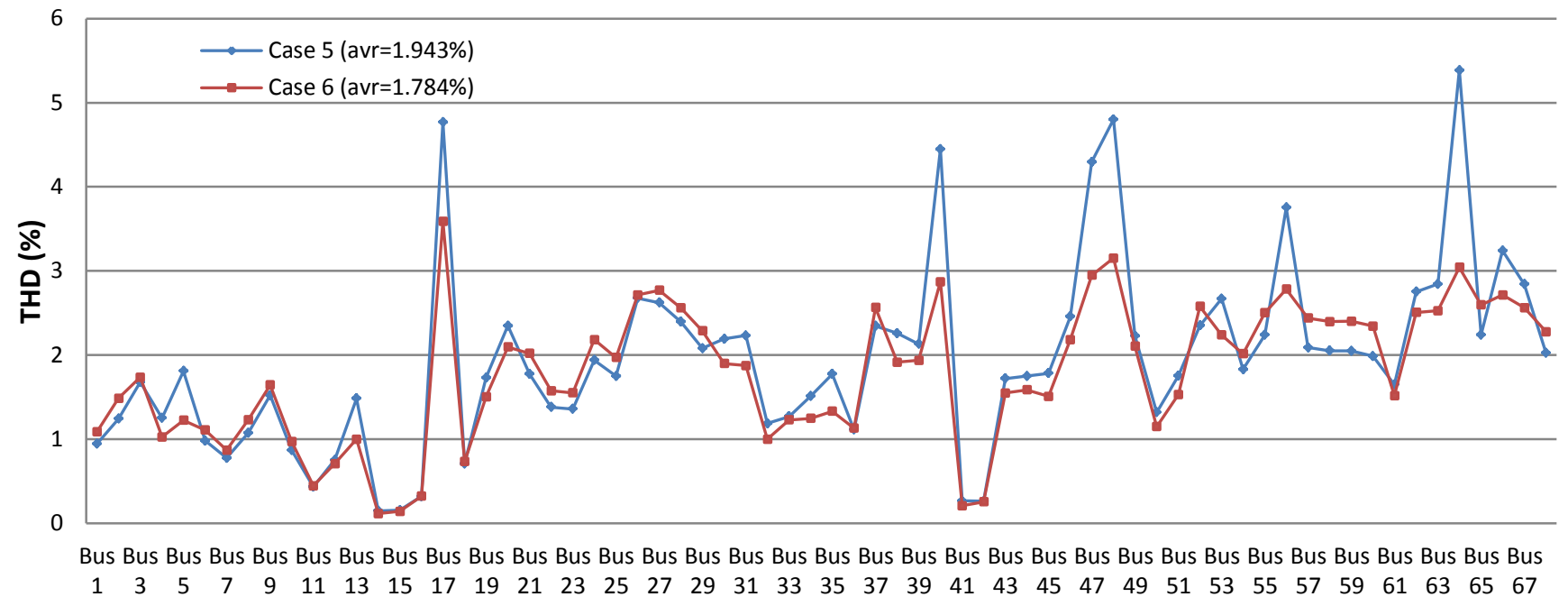

Figure 7. All network buses $95^{\text {th }}$ percentiles THD values for Case 5 and Case 6 


\section{ACCEPTED VERSION OF THE PAPER}

\section{REFERENCES} 2014 93, 2005. 119, pp. 199-206, 2015. International, 2010, pp. 194-199.
George J. Wakileh, Power Systems Harmonics: Fundamentals, Analysis and Filter Design. New York: Springer, 2001

Assessment of Emission Limits for Distorting Loads in MV and HV Power Systems. IEC Standard 61000-3-6:1996, 1996

IEEE Recommended Practices and Requirements for Harmonic Control in Electrical Power Systems. IEEE Standard 519:2014,

R. M. Gantiv and J. V. Milanovic, "Qualitative and quantitative analysis of voltage sags in networks with significant penetration of embedded generation," Euro. Trans. Electr. Power, no. 15, pp. 77-

I. N. Santos, V. Cuk, P. M. Almeida, M. H. J. Bollen, and P. F. Ribeiro, "Considerations on hosting capacity for harmonic distortions on transmission and distribution systems," EPSR, no.

Wang Fei, J. L. Duarte, and M. A. M. Hendrix, "Analysis of harmonic interactions between DG inverters and polluted grids," in Proc. Energy Conference and Exhibition (EnergyCon), 2010 IEEE

D. Patel, R. K. Varma, R. Seethapathy, and M. Dang, "Impact of wind turbine generators on network resonance and harmonic distortion," in Proc. Electrical and Computer Engineering (CCECE), 2010 23rd Canadian Conference on, 2010, pp. 1-6.

M. T. Arif, A. M. T. Oo, A. S. Ali, and G. Shafiullah, "Impacts of storage and solar photovoltaic on the distribution network," in Proc. Universities Power Engineering Conference (AUPEC), 2012 22nd Australasian, 2012, pp. 1-6. http://www2.nationalgrid.com/UK/Industryinformation/Electricity-transmission-operational-data/DataExplorer/

[10] T. Guo and J. V. Milanovic, "Probabilistic Framework for Assessing the Accuracy of Data Mining Tool for Online Prediction of Transient Stability," IEEE Trans. on Power Systems, vol. 29, no. 1, pp. 377-385, 2014.

[11] The University of Edinburgh, "Matching Renewable Electricity Generation With Demand " Scottish Executive, Edinburgh 2006.

[12] National Renewable Energy Laboratory. PVWatts Viewer [Online].Available: http://gisatnrel.nrel.gov/PVWatts Viewer/index.html

[13] J. Meyer, M. Bollen, H. Amaris, A. M. Blanco, A. Gil de Castro, J. Desmet, M. Klatt, L. Kocewiak, S. Ronnberg, and K. Yang, "Future work on harmonics - some expert opinions Part II supraharmonics, standards and measurements," in Proc. 2014 16th International Conference on Harmonics and Quality of Power (ICHQP), 2014, pp. 909-913.

[14] Au Mau Teng and J. V. Milanovic, "Establishing Harmonic Distortion Level of Distribution Network Based on Stochastic Aggregate Harmonic Load Models," IEEE Trans. Power Delivery, vol. 22, no. 2, pp. 1086-1092, 2007.

[15] S. K. Rönnberg, A. G. d. Castro, M. H. J. Bollen, A. MorenoMunoz, and E. Romero-Cadaval, "Supraharmonics from power electronics converters," in Proc. 2015 9th International Conference on Compatibility and Power Electronics (CPE), 2015, pp. 539-544. 